\title{
Distal Transradial Access in the Anatomic Snuffbox for Diagnostic Cerebral Angiography
}

\author{
(D) P. Patel, (D) N. Majmundar, (DI. Bach, (D) V. Dodson, (D) F. Al-Mufti, (D). Tomycz, and (D) P. Khandelwal
}

\begin{abstract}
SUMMARY: The aim of this study was to describe the feasibility, technique, and safety of distal transradial access in the anatomic snuffbox for diagnostic cerebral angiography. A retrospective review of diagnostic cerebral angiograms obtained during a 6-month period with distal transradial access was performed. Thirty-four successful procedures were performed via distal transradial access. There were 4 failed attempts. This single-center experience using distal transradial access suggests that this technique is safe and effective.
\end{abstract}

ABBREVIATIONS: dTRA = distal transradial access; TFA = transfemoral approach; TRA = transradial approach

W hile the transradial approach (TRA) has been used by cardiologists for coronary angiography since its first reported use in 1989, the TRA has been more recently adopted by neurointerventionalists. ${ }^{1}$ At our institution, the transfemoral approach (TFA) was traditionally used for diagnostic cerebral angiograms until last year, when we started using the TRA for diagnostic cerebral angiograms. The benefits of the TRA include reduced access site complications, increased patient comfort, earlier ambulation, and decreased time for postprocedural monitoring. Thus, the TRA was adopted for routine use at our institution for diagnostic cerebral angiography, and the TFA is used when access through the radial artery is difficult. However, the TRA also has its limitations and complications, including radial artery spasm, thrombotic occlusion, hematoma, pseudoaneurysm, arteriovenous fistula, positioning difficulties, the depth of the radial artery in large arms, and compartment syndrome. ${ }^{2}$

Distal transradial access (dTRA) involves accessing the radial artery immediately above the scaphoid or trapezium bones via the anatomic snuffbox. ${ }^{3}$ dTRA limits many of the complications of the TRA. Cannulation and sheath placement of the radial artery through the anatomic snuffbox can be performed with the arm in a neutral position, thus foregoing total supination of the wrist and allowing the patient to place the forearm in a more

Received May 5, 2019; accepted after revision July 1.

From the Departments of Neurosurgery (P.P., N.M., V.D., L.T., P.K.) and Neurology (I.B.), Rutgers New Jersey Medical School, Newark, New Jersey; and Department of Neurology and Neurosurgery (F.A.-M.), Westchester Medical Center, New York Medical College, Valhalla, New York.

Please address correspondence to Priyank Khandelwal, MD, Department of Neurosurgery, Rutgers New Jersey Medical School, 90 Bergen St, Suite 8100 , Newark, NJ 07103; e-mail: pk544@njms.rutgers.edu

http://dx.doi.org/10.3174/ajnr.A6178 natural position. Studies of dTRA in interventional cardiology procedures have demonstrated technical and procedural success, markedly reduced access site complications, and decreased rates of radial artery occlusion.,

\section{MATERIALS AND METHODS}

We performed a retrospective chart review from a prospectively maintained data base of all patients undergoing diagnostic cerebral angiography from October 2018 through March 2019. Two attending physicians and 1 neuroendovascular fellow performed dTRA for the study. All had received formal training either in their fellowship or during a dedicated dTRA training course. This approach was only used for diagnostic cerebral angiography and not for interventional procedures because interventional procedures require larger catheters. Patients who had CT angiography of the head and neck available were studied to assess any anatomic variation before undergoing diagnostic cerebral angiography. Patients were excluded from the study if the caliber of the radial artery was $<2 \mathrm{~mm}$, if there was a need for an extensive diagnostic study including the left vertebral artery or thyrocervical trunk, if the radial artery was occluded, if there was evidence of an aberrant subclavian artery or variation of the aortic arch, or due to patient preference. Procedures were performed with a local anesthetic with conscious sedation. Patient demographics, procedural complications, procedural time, and postprocedural care information were collected. Possible major complications included radial artery perforation, pseudoaneurysm formation, or hand ischemia. Possible minor complications included formation of a hematoma or pain at the puncture site. The retrospective study was approved by the Rutgers New Jersey Medical School Institutional Review Board. 


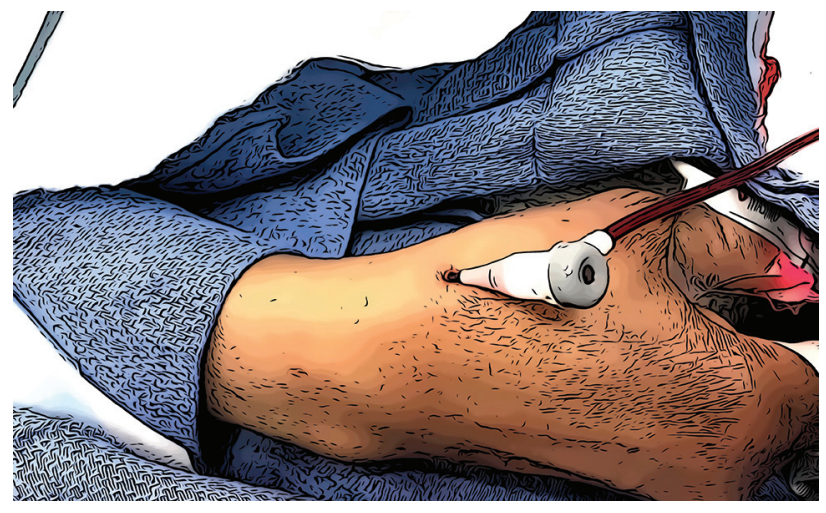

FIG 1. A 5F short vascular sheath in the distal radial artery at the anatomic snuffbox. The hand is secured in a slightly flexed and ulnardeviated position.

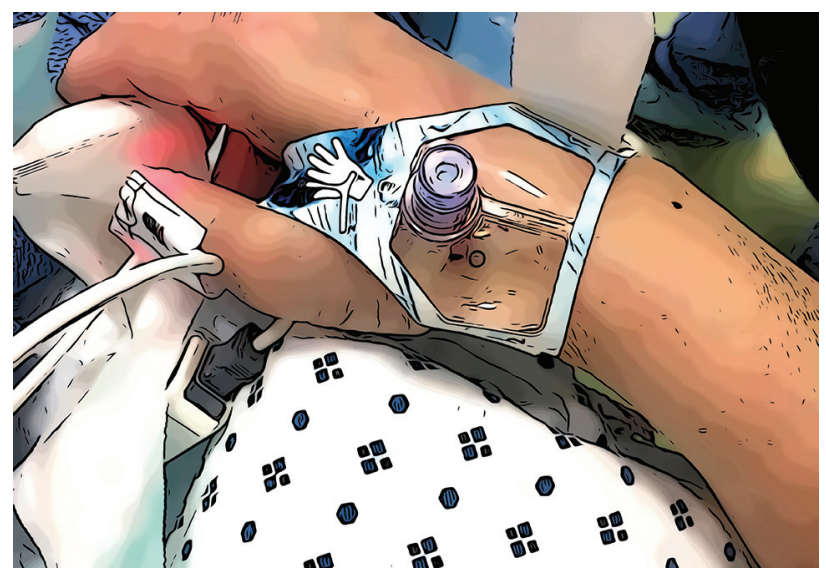

FIG 2. External compression device for closure of the arteriotomy site.

\section{Procedural Technique}

Right radial artery diameter was measured in the anatomic snuffbox using sonography in all patients. If the radial artery diameter was $<2 \mathrm{~mm}$, a different access site was chosen. The patient's right arm was kept in a midprone position and elevated to the level of the body. The hand was kept slightly flexed and deviated toward the ulna to straighten the radial artery and to bring it to a more superficial plane. Two-to- $3 \mathrm{~mL}$ of lidocaine (1\%) was injected in the skin of the anatomic snuffbox. By means of a 2-cm 21-ga micropuncture needle, the radial artery was punctured with sonographic guidance using a single-wall technique. A 5F Prelude Ideal (Merit Medical, South Jordan, Utah) or a 5F Glidesheath Slender (Terumo, Somerset, New Jersey) vascular sheath was introduced over the wire (Fig 1). Next, $2.5 \mathrm{mg}$ of verapamil and $200 \mathrm{mcg}$ of nitroglycerin were injected intra-arterially after hemodilution. A radial artery roadmap was then obtained. A 5F diagnostic Sim 2 catheter (Terumo) was introduced over a 0.035 -inch angled glide wire. The Sim 2 catheter was formed either in the ascending or descending aorta. After we completed the diagnostic cerebral angiography, the sheath was removed. An external compression device was applied over the puncture site to achieve patent hemostasis. We used either a standard TR Band (Terumo)

\begin{tabular}{ccccc} 
Demographics & & & \\
\hline $\begin{array}{c}\text { Mean Age } \\
(\mathrm{yr})\end{array}$ & $\begin{array}{c}\text { Mean No. of } \\
\text { Female }\end{array}$ & $\begin{array}{c}\text { Vessels } \\
\text { Catheterized }\end{array}$ & $\begin{array}{c}\text { Mean Total } \\
\text { Fluoroscopy } \\
\text { Time (min) }\end{array}$ & $\begin{array}{c}\text { Fluoroscopy } \\
\text { Time per } \\
\text { Vessel (min) }\end{array}$ \\
\hline $54.5 \pm 11.5$ & $50 \%$ & $3.8 \pm 1.4$ & $14.4 \pm 6.5$ & $3.9 \pm 1.4$ \\
\hline
\end{tabular}

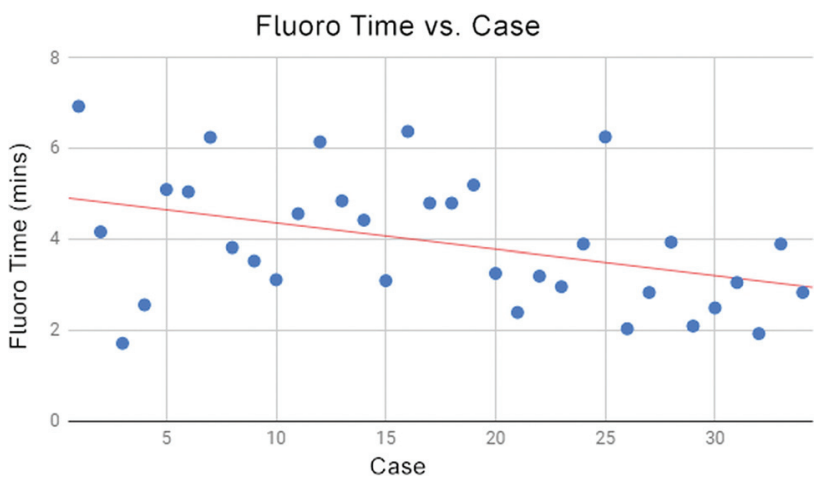

FIG 3. Fluoroscopy time (in minutes) per vessel decreases with increasing operator experience.

after removing the hard plastic from it or the PreludeSync Distal Band (Merit Medical), a dedicated distal radial closure band (Fig 2). Hand perfusion patency was confirmed with continuous pulse oximetry on the right thumb.

\section{RESULTS}

A total of 129 cerebral angiograms were obtained during the study period, of which 34 were successfully performed in 31 patients using dTRA. Patients ranged from 33 to 78 years of age (Table). Four patients had failed attempts of dTRA due to severe vasospasm of the radial artery in the proximal segment. In 2 of these patients, conventional TRA was performed after resolution of the spasm. The other 2 patients were converted to TFA. These failures occurred earlier in our transition to dTRA. An average of 3.8 vessels (range, 1-6 vessels) were catheterized per procedure. After successful access, we were able to catheterize all intended vessels. No major complications were recorded. The only reported minor complication was pain of the right wrist in 2 patients, which lasted 1 week. The 12 patients who had previously undergone the TFA reported that they preferred dTRA. Fluoroscopy time per vessel decreased with time, demonstrating that the learning curve associated with this novel procedure can be overcome with experience (Fig 3). While postprocedurally only 2 hours of nursing supervision was required, the average elapsed time between the end of the procedure and discharge was 3 hours 15 minutes due to a variety of patient-related factors and not due to extended monitoring requirements.

\section{DISCUSSION}

This retrospective review of dTRA cases found no major complications. While this finding is consistent with those in other studies investigating dTRA, studies that directly compare the complication rates of dTRA and TRA are scarce. It has, however, been demonstrated by Koutouzis et $\mathrm{al}^{4}$ that while the 


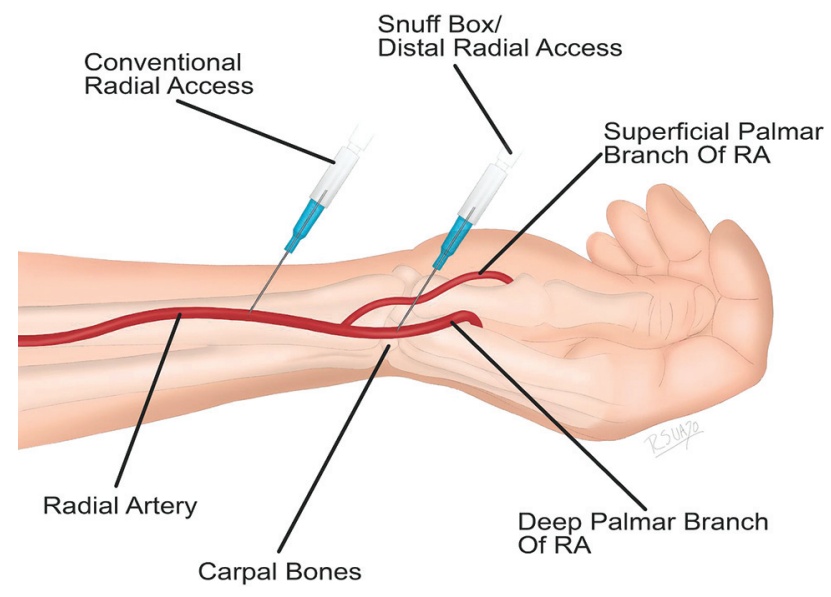

FIG 4. Distal radial artery course through the anatomic snuffbox. Note that the superficial palmar artery branches off before the radial artery enters the anatomic snuffbox.

complication rates of both techniques are similar, dTRA is associated with shorter manual hemostasis. They also, however, found an increased time to cannulation associated with dTRA, highlighting the importance of clinical experience in learning this novel technique.

Radial artery occlusion is a serious concern with the TRA, reported to occur in $1 \%-10 \%$ of coronary procedures. ${ }^{5}$ While radial artery occlusion is generally asymptomatic and rarely affects a patient's quality of life, it can limit future access in that arm. The distal part of the radial artery passes deep through the anatomic snuffbox and continues distally as the deep palmar arch of the hand. Most important, for dTRA, the radial artery is accessed distal to the origin of the superficial palmar branch of the radial artery (Fig 4). This is important in preventing postprocedural hand ischemia because the superficial palmar arch is not at risk of occlusion if the distal radial artery becomes occluded during or after interventional procedures. ${ }^{6}$ With dTRA, any occlusion of the radial artery is distal to the takeoff of the superficial palmar branch of the radial artery. Therefore, if dTRA results in occlusion of the distal radial artery, anterograde blood flow is preserved via the superficial palmar arch.

In our dTRA case series, 4 patients had to be converted to a different access site due to radial artery vasospasm. Overall, the dTRA failure rate has been reported to be around 5.8\%., ${ }^{2,4,6,7}$ Spasm is a well-known complication of the TRA and dTRA, though the use of preprocedural sonography to evaluate radial artery diameter can mitigate its risk. The size of the radial artery can be up to $20 \%$ smaller in the snuffbox. In addition, the radial artery tends to be smaller in female patients. ${ }^{8}$ Injudicious selection of patients for dTRA may lead to higher conversion rates to different access sites and an increased number of multiple trials before successful cannulation. Sonographic assistance is therefore highly recommended and is considered mandatory at our institution for any radial approach. Preprocedural radial artery evaluation can limit many access complications that can arise. Experience with the procedure is also important. Training for the dTRA is straightforward. Operators, including neuroendovascular fellows, attended a dedicated dTRA course with hands-on training with manikins and cadavers. As with most procedures, there is a learning curve associated with a new technique. Fluoroscopy time and the number of failed trials decreased with increased experience (Fig 3).

\section{CONCLUSIONS}

We demonstrated that the dTRA can provide an alternative approach to conventional radial or transfemoral approaches, with some potential advantages. In our experience, this technique is safe and effective and can potentially reduce procedural costs compared with the more conventional approaches, particularly the TFA. While we did not encounter any major complications, this approach needs to be studied in a larger patient dataset to elucidate its safety and feasibility.

Disclosures: Priyank Khandelwal—UNRELATED: Travel/Accommodations/Meeting Expenses Unrelated to Activities Listed: American College of Cardiology, Comments: \$2000 as a speaker.* Luke Tomycz-RELATED: Consulting Fee or Honorarium: Philips Neuro, Comments: honorarium of $\$ 1500$ and flight expenses to participate in meeting in Warsaw in June 2019.* *Money paid to individual.

\section{REFERENCES}

1. Snelling BM, Sur S, Shah SS, et al. Transradial cerebral angiography: techniques and outcomes. J Neurointerv Surg 2018;10:874-81 CrossRef Medline

2. Ziakas A, Koutouzis M, Didagelos M, et al. Right arm distal transradial (snuffbox) access for coronary catheterization: initial experience. Hellenic J Cardiol 2018 Oct 30. [Epub ahead of print] CrossRef Medline

3. Babunashvili A, Dundua D. Recanalization and reuse of early occluded radial artery within 6 days after previous transradial diagnostic procedure. Cathet Cardiovasc Intervent 2011;77:530-36 CrossRef Medline

4. Koutouzis M, Kontopodis E, Tassopoulos A, et al. Distal versus traditional radial approach for coronary angiography. Cardiovasc Revasc Med 2018 Oct 2. [Epub ahead of print] CrossRef Medline

5. Soydan E, Akin M. Coronary angiography using the left distal radial approach - An alternative site to conventional radial coronary angiography. Anatol J Cardiol 2018;19:243-48 CrossRef Medline

6. McCarthy $\mathrm{D}$, Chen S, Brunet MC, et al. Distal radial artery access in the anatomical snuffbox for neurointerventions: case report. World Neurosurg 2019;122:355-59 CrossRef Medline

7. Valsecchi O, Vassileva A, Cereda AF, et al. Early clinical experience with right and left distal transradial access in the anatomical snuffbox in $\mathbf{5 2}$ consecutive patients. I Invasive Cardiol 2018;30:218-23

8. Kim Y, Ahn Y, Kim MC, et al. Gender differences in the distal radial artery diameter for the snuffbox approach. Cardiol J 2018;25:639-41 CrossRef Medline 